\title{
Development of the Pan-Arctic Snowfall Reconstruction: New Land-Based Solid Precipitation Estimates for 1940-99
}

\author{
J. E. CHERry \\ International Arctic Research Center, and Arctic Region Supercomputing Center, University of Alaska Fairbanks, Fairbanks, Alaska \\ L.-B. TREMBLAY \\ Department of Atmospheric and Oceanic Sciences, McGill University, Montreal, Quebec, Canada \\ M. STIEGLITZ \\ School of Civil and Environmental Engineering, and School of Earth and Atmospheric Sciences, Georgia Institute of Technology, \\ Atlanta, Georgia \\ G. GONG \\ Department of Earth and Environmental Engineering, Columbia University, New York, New York \\ S. J. DÉRY \\ Environmental Science and Engineering Program, University of Northern British Columbia, Prince George, British Columbia, Canada
}

(Manuscript received 24 April 2006, in final form 5 January 2007)

\begin{abstract}
A new product, the Pan-Arctic Snowfall Reconstruction (PASR), is developed to address the problem of cold season precipitation gauge biases for the 1940-99 period. The method used to create the PASR is different from methods used in other large-scale precipitation data products and has not previously been employed for estimating pan-arctic snowfall. The NASA Interannual-to-Seasonal Prediction Project Catchment Land Surface Model is used to reconstruct solid precipitation from observed snow depth and surface air temperatures. The method is tested at four stations in the United States and Canada where results are examined in depth. Reconstructed snowfall at Dease Lake, British Columbia, and Barrow, Alaska, is higher than gauge observations. Reconstructed snowfall at Regina, Saskatchewan, and Minot, North Dakota, is lower than gauge observations, probably because snow is transported by wind out of the Prairie region and enters the hydrometeorological cycle elsewhere. These results are similar to gauge biases estimated by a water budget approach. Reconstructed snowfall is consistently higher than snowfall from the 40-yr European Centre for Medium-Range Weather Forecasts (ECMWF) Re-Analysis (ERA-40) but does not have a consistent relationship with snowfall derived from the WMO Solid Precipitation Intercomparison Project correction algorithms. Advantages of the PASR approach include that 1) the assimilation of snow depth observations captures blowing snow where it is deposited and 2) the modeling approach takes into account physical snowpack evolution. These advantages suggest that the PASR product could be a valuable alternative to statistical gauge corrections and that arctic ground-based solid precipitation observing networks might emphasize snow depth measurements over gauges.
\end{abstract}

\section{Introduction}

The arctic water cycle is a key component of the global climate system and one that is changing quickly

Corresponding author address: Jessie Ellen Cherry, International Arctic Research Center, and Arctic Region Supercomputing Center, University of Alaska Fairbanks, P.O. Box 757335, Fairbanks, AK 99775-7335.

E-mail: jcherry@iarc.uaf.edu
(Vörösmarty et al. 2001). Within this cycle, snowfall is a dominant feature that modulates radiative balance (Wang and Key 2003), air temperature (Groisman et al. 1994), ground temperature (Stieglitz et al. 2003), geomorphology (Mackay 1987; Grab 2005), biogeography (Sturm et al. 2001; Chapin et al. 2005), large-scale climate dynamics (Barnett et al. 1989; Cohen and Entekhabi 2001; Gong et al. 2002, 2003a,b, 2004), and runoff (Lammers et al. 2001; Peterson et al. 2002; McClelland et al. 2004). Observations show long-term trends in 
all of these features (Chapman and Walsh 1993; Serreze et al. 2000; Houghton et al. 2001; ACIA 2004). The amount and distribution of snowfall throughout the Arctic is impacted by each of these climatic factors in turn through complex feedbacks.

Of all these factors, snowfall may be the most difficult to measure. The simplest bucket gauge and the most sophisticated shielded gauge share similar systematic biases: they disrupt the normal flow of snow in the atmospheric boundary layer. Snow preferentially falls away from the gauge. In addition, there are many unsystematic biases like unrepresentative gauge siting, mechanical failures, snow freezing around the gauge, etc. (Goodison et al. 1998). Improving estimates of frozen precipitation is a priority for several multiagency programs including the Global Energy and Water Cycle Experiment (GEWEX; http://www.gewex.org/), Study of Environmental Arctic Change (SEARCH; Morison et al. 2001), the Northern Eurasia Earth Science Partnership Initiative (NEESPI; http://neespi.gsfc.nasa.gov/ science/science.html), and the Arctic Community-wide Hydrologic Analysis and Monitoring Program (http:// arcticchamp.sr.unh.edu/). Finally, estimates of snowfall are crucial for predicting water resources in snowdominated hydrologic regimes (Cherry et al. 2005a; Barnett et al. 2005).

Previous efforts to estimate "true" precipitation, liquid and frozen, include correcting gauges according to the amount of precipitation they catch relative to a well-tested reference gauge or a pit. This correction is typically a regression function based on meteorological parameters such as wind speed and temperature and has shown gauge errors of up to $80 \%-120 \%$ for snowfall (Yang et al. 1998, 2000, 2005). Biases for liquid precipitation are smaller by an order of magnitude (Sevruk and Hamon 1984) and will not be addressed here. The World Meteorological Organization (WMO) supported an extensive effort by Goodison et al. (1998) and contributors to compare solid precipitation between different gauges in this way. Corrections published in this report have led to a series of new solid precipitation estimates (Yang et al. 1998, 2000, 2005). Adam and Lettenmaier (2003) published an excellent summary of gauge corrections, including those by Legates and Willmott (1990), Groisman (1998), Groisman et al. (1991), Mekis and Hogg (1999), and Willmott and Matsuura (2001), and show how they can be used to adjust gridded precipitation datasets. A problem associated with the statistical correction approach may be that it does not account for gauge siting and other unsystematic biases (Goodison et al. 1998; Cherry et al. 2005b).

Other efforts to estimate solid and liquid precipita- tion include radar measurements (Marshall and Gunn 1952), merged gauge-satellite analysis products (Xie and Arkin 1997; Huffman et al. 1997), budgetary approaches (Fekete et al. 1999, 2004; Berezovskaya et al. 2004), and global climate reanalyses (Kalnay et al. 1996; Uppala et al. 2005). Disadvantages to these approaches include a relatively short satellite era, errors associated with the indirect measurement of precipitation from satellites (Arkin and Ardanuy 1989), inconsistent levels of assimilated observations in the reanalyses (Hagemann et al. 2005), and errors associated with interpolating or assimilating sparse observations of a heterogeneous substance to large grid cells (Hulme and New 1997).

Our approach to estimating precipitation is different from the above-mentioned methods used in other large-scale precipitation data products and has not previously been employed for estimating pan-arctic snowfall. We focus on solid precipitation over the arctic hydrologic domain, because of the large uncertainties there. We use historical observations of daily snow depth, the National Aeronautics and Space Administration (NASA) Seasonal-to-Interannual Prediction Project Catchment Land Surface Model, observed meteorological forcing, and a simple data assimilation technique to reconstruct the amount of snow that must have fallen to produce the observed snow depth, taking into account compaction, sublimation, evaporation, and other physics of the snowpack. The resulting product will be the Pan-Arctic Snowfall Reconstruction (PASR). In the following pages we will briefly describe the proof-of-concept study published in Cherry et al. (2005b), describe the model and the datasets used for forcing and restoring, compare reconstructions from four different stations in the arctic catchment to gauge, corrected gauge, and gridded snowfall products, and discuss the results. Comparison of the full domain of the PASR product (2988 stations) to other arctic solid precipitation products will be reserved for a separate paper so that the four test stations can be studied in depth here.

\section{Methods}

\section{a. Proof of concept}

The snowfall reconstruction method used to create the PASR was developed and tested using data from Reynolds Creek Experimental Watershed (RCEW) in Idaho and is thoroughly described in Cherry et al. (2005b). RCEW is not in the arctic hydrologic catchment but was used for the proof of concept because it receives a large amount of solid precipitation and has had a well-documented, hourly climate and snow water 
equivalent record for nearly 20 yr. Because geography and meteorological conditions vary widely across the pan-arctic domain, the present paper demonstrates the method at four arctic sites with differing conditions. Throughout this paper the terms "arctic" and "the Arctic" will refer to the domain of the arctic hydrological catchment and the overlying atmosphere, respectively. We reconstruct snowfall by forcing a snow model with observed meteorological data. In this case, we use gauge precipitation as an initial guess of the actual precipitation $\left(P_{\text {ini }}\right)$. As snow accumulates, the snowpack compacts and is subjected to evaporation, condensation, sublimation, and other snow physics represented in the model. At the end of each time step, the model snow depth is compared to the observed snow depth and the difference is considered "excess" $(S)$, which can be positive or negative. Assuming a density of freshly fallen snow of $150 \mathrm{kgm}^{-3}$, this difference is then added to the initial guess of solid precipitation to reconstruct how much actual snowfall must have occurred $\left(P_{\text {rec }}\right)$. This can be written as follows:

$$
P_{\text {rec }}=P_{\text {ini }}+S+e
$$

where $e$ represents all physical and numerical errors in the reconstruction. Physical errors are associated with model snow physics that do not precisely match the actual snow physics at any given time. An example of a physical error is when the modeled compaction of the snowpack does not match the observed compaction. Numerical errors are those introduced by the restoring procedure and are shown to be small (Cherry et al. 2005b), even for the large snowfall amount that occurs at RCEW. While excess $(S)$ may be negative (i.e., the initial guess of snowfall is an overestimate of the actual amount), net reconstructed solid precipitation can only be zero or positive.

This method was shown to reduce errors of snowfall estimates by $30 \%$ over corrected gauge observations at RCEW, when a number of meteorological parameters were used to drive the evolution of the snowpack, including surface air temperature (SAT), precipitation, incoming shortwave radiation, downwelling longwave radiation, relative humidity, and wind speed (Cherry et al. 2005b). However, SAT and gauge precipitation, along with snow depth, are the only abundant longterm meteorological observations available in the Arctic. This data constraint was tested at RCEW by forcing the land surface model with only SAT and assuming that the snow or soil surface temperature is equal to SAT, which resulted in up to $3 \%$ additional error per snow month. While errors introduced by lowering the number of snowpack-forcing parameters are significant (an average of $24 \%$ per year for an 8 -month snow sea- son at RCEW), they are much smaller than the typical values of gauge undercatch in the Arctic of $80 \%-120 \%$ (Yang et al. 1998, 2000, 2005). The error estimates at RCEW were made possible by the high level of consistency between snow water equivalent from a snow course and a snow pillow, which provided a good estimate of true precipitation.

\section{b. Arctic reconstruction}

\section{1) Model}

The model used to reconstruct solid precipitation is the NASA Seasonal-to-Interannual Prediction Project (NSIPP) Catchment Land Surface Model (CLSM). This is a state-of-the-art land surface model based conceptually on TOPMODEL (Beven and Kirkby 1979), which uses the catchment as the fundamental unit of hydrological response. A topographic index in the model is used to estimate subgrid-scale heterogeneity in soil saturation, snow cover, etc. This topographic index is calculated from a 30 -arc second resolution (approximately $1 \mathrm{~km}$ ) digital elevation model from the U.S. Geological Survey. The snow model in CLSM is that of Lynch-Stieglitz (1994) and has been used successfully in a number of applications (Lynch-Stieglitz 1994; Rind et al. 1997; Stieglitz et al. 1999, 2000, 2001, 2003; Déry et al. 2004, 2005a,b; Cherry et al. 2005b). This model has three snow layers and includes growth and ablation processes such as melting, refreezing, compaction, sublimation, and heat exchange with a six-layer thermodynamic soil model; details are described in the 1994 paper. As in Cherry et al. (2005b), the major modification to the model of Lynch-Stieglitz (1994) is that albedo is modeled explicitly. The model was also modified to employ a specified boundary condition for the snow/ soil surface temperature (SAT). The equations for snow albedo are based on Hansen et al. (1983), as described by Stieglitz et al. (2001). When snow is freshly fallen (density $=150 \mathrm{~kg} \mathrm{~m}^{-3}$ ), albedo is 0.82 and when snow has aged and compacted it has a minimum albedo of 0.50 at 50 days. This parameterization is based on observations by the U.S. Army Corps of Engineers (1956). Further information about the physics and parameterizations of CLSM is given by Koster et al. (2000) and Ducharne et al. (2000).

\section{2) DatA}

Eight datasets are used to create the full PASR; a subset of these is used for the four test stations shown here in depth. Daily snow depth data are obtained from the Daily Snow Depth dataset (CSD; Environment Canada 2000), Historical Soviet Daily Snow Depth ver- 
sion 2.0 (HSDSDv2; NSIDC 1999), Global Surface Summary of the Day (GLOBALSOD; NOAA/NCDC 2005), and First Order Summary of the Day (FSOD; NOAA/NCDC 1998). Daily gauge precipitation and temperature minimum and maximum data were obtained from GLOBALSOD, FSOD, the Global Daily Climatology Network, version 1 (GDCN; NOAA/ NCDC 2002), the Global Historical Climatology Network, version 1 (GHCN; NOAA/NCDC 2004), and the Canadian Daily Climate Data (CDCD; Environment Canada 2002). Elevation for the snow depth stations was obtained from ETOPO5 (NOAA/NGDC 1993). Duplicate stations were identified by national or WMO station identification number and/or location to 0.1 min. The locations of all pan-arctic snow depth stations are shown in Fig. 1, as well as the delineation of the arctic hydrologic catchment. Figure 1 also shows the locations of the four sample stations where results are analyzed in depth (identified by stars). The catchment mask is from R-ArcticNet version 3.0 (Lammers and Shiklomanov 2000, now updated). Figure 2 shows the number of snow depth, precipitation, and surface air temperature stations as a function of time in seven of the major arctic drainage basins and the total for all pan-arctic river basins. The total number of reconstructed snowfall time series is 2988 , which is approximately the number of independent (i.e., nonduplicate) stations in the different snow depth datasets that fall inside the pan-arctic hydrologic catchment. Finally, comparisons are made between the four PASR test stations and 1) solid precipitation in the corrected gauge dataset by Yang et al. (2005; available online at http:// www.uaf.edu/water/faculty/yang/yang.html); 2) the snowfall fields from the 40-yr European Centre for Medium-Range Weather Forecasts (ECMWF) ReAnalysis (ERA-40; ECMWF 2003; Uppala et al. 2005); and 3) gauge precipitation biases developed through a water balance approach by Fekete et al. (1999, 2004).

\section{3) Reconstruction}

The reconstructions are done by running the NSIPP CLSM at points where daily snow depth and SAT time series exist. During initial development of the PASR the authors did not wish to extrapolate snowfall over entire catchments or spatially interpolate between stations. For this reason, the NSIPP CLSM is run as a column (1D) that has three subpartitions to statistically represent subgrid-scale heterogeneity in snow and soil properties such as water saturation. Future use of the distributed (3D) capabilities of the NSIPP CLSM with the Déry and Yau (2002) blowing snow model is remarked upon in the discussion and conclusions sections below.
At each snow depth station, we use daily precipitation and SAT forcing for the reconstruction from the nearest available station. The location of forcing data is kept the same for the entire period; if two stations are equidistant from the snow depth station the station with more existing data is used. In most locations, precipitation and minimum and maximum SAT were observed at approximately the same location where the snow depth was measured. Figures 3 and 4 show the distance of the precipitation and SAT forcing observations from the snow depth station, according to the location metadata associated with each dataset. Distances between stations were calculated along geographic great circles, but elevation differences were not considered.

While precipitation is referred to as a forcing variable, it should be noted that this method is not sensitive to the initial guess of precipitation. An alternative initial guess for precipitation could easily be the change in observed snow depth multiplied by the density of freshly fallen snow. Precipitation forcing was interpolated from daily observations down to a 20-min time step for the model runs. Precipitation was assumed to be distributed evenly throughout the day. SAT was interpolated linearly from the daily temperature minimum and maximum. The daily temperature maximum was assumed to occur $2 \mathrm{~h}$ after local solar noon and the minimum was assumed to occur $1 \mathrm{~h}$ before local sunrise. These interpolation algorithms are kept extremely simple because there are few hourly measurements from the Arctic to support the use of more complex schemes. Also, strong diurnal cycles of temperature and precipitation are associated with atmospheric convection (Dai et al. 1999). Such convection is suppressed in the Arctic by the strong atmospheric inversion, which is caused by high surface albedo and low incoming radiation, and typically exists for much of the cold season (Serreze and Barry 2005). Units for precipitation, SAT, and snow depth were converted to millimeters, degrees Celsius, and meters, respectively.

It should be emphasized that while the model is run with a 20-min time step, the intrinsic scale of the reconstruction is limited by the daily snow depth measurement. The availability of SAT minima and maxima provide some subdaily information for forcing the snow model, but the assumption of precipitation occurring evenly throughout the day is unrealistic. Instead, the subdaily time step should be thought of as Newtonian relaxation or nudging toward the observed snow depth value. A 20 -min to 1 -h relaxation time scale has been used successfully in a number of studies employing the assimilation of synoptic observations (Kalnay 2003).

Missing daily data between 1 January 1940 and 31 December 1999 were in-filled in the following way. For 


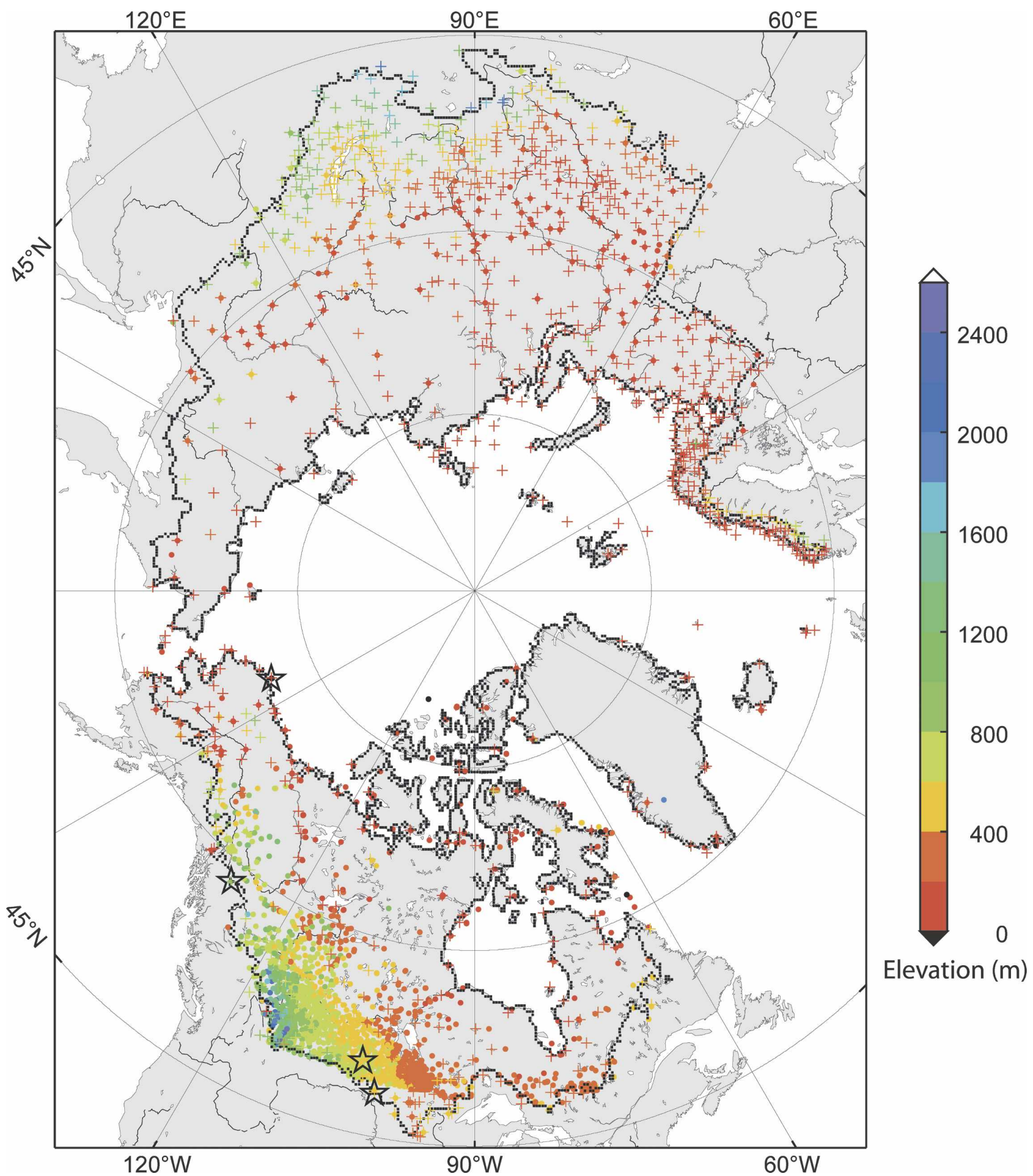

FIG. 1. Locations of the daily snow depth stations used in the PASR dataset. Projection is polar stereographic. Scale denotes elevation $(\mathrm{m})$. The black line delineates the arctic hydrological catchment. Stations from the Global Summary of the Day dataset (NOAA/NCDC 2005) are shown as crosses because they are only available for the period 1994-99. Stations shown as circles (sometimes beneath crosses) typically have long-term observations. Stars denote stations where the reconstruction results are examined in depth. 

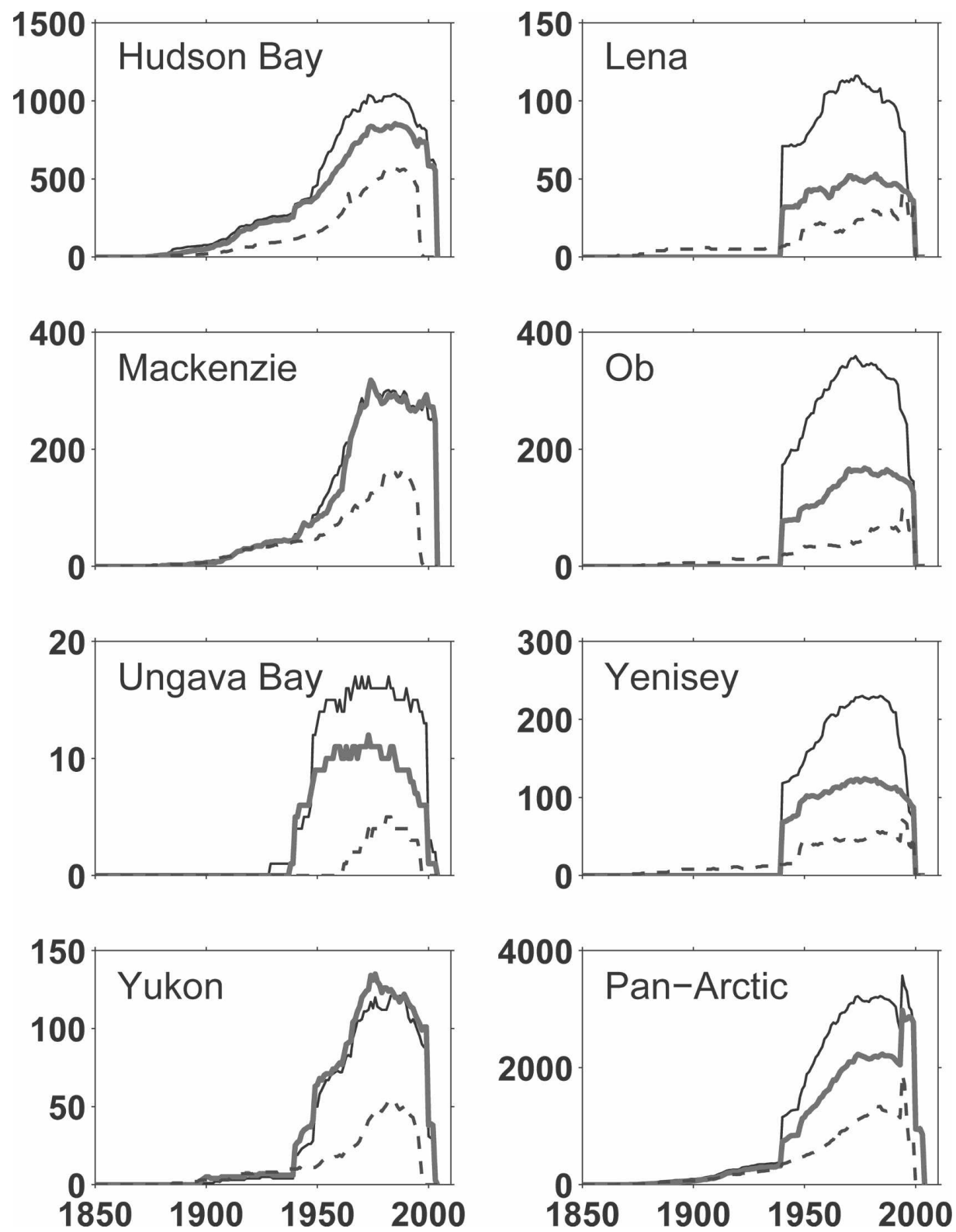

FIG. 2. Number of stations per year where daily observations are made, for major arctic subcatchments and the entire pan-arctic catchment. The thin line denotes precipitation gauges, the thick line denotes temperature stations, and the dashed line denotes snow depth stations. Note that the scale on the $y$ axis changes from basin to basin. The sharp decline of observations at the start of the twenty-first century is a combined effect of station shutdown and lags in data reporting.

daily temperature or precipitation data, if three days in a row or fewer are missing, they are linearly interpolated from the temporally neighboring values. If more than three days are missing, the missing days are replaced by monthly climatological values. The threshold of three days was chosen because it is approximately the time of a synoptic event. For snow depth, the threshold was extended to 16 days because of the long residence time of snow on the ground, relative to precipitation.

The model runs are done by specifying the snow surface temperature or soil surface temperature (when there is no snow) with SAT. The initial guess of precipitation (solid and liquid) is made from gauge observations. Solid precipitation is reconstructed by restoring to observed snow depth and adding the excess 


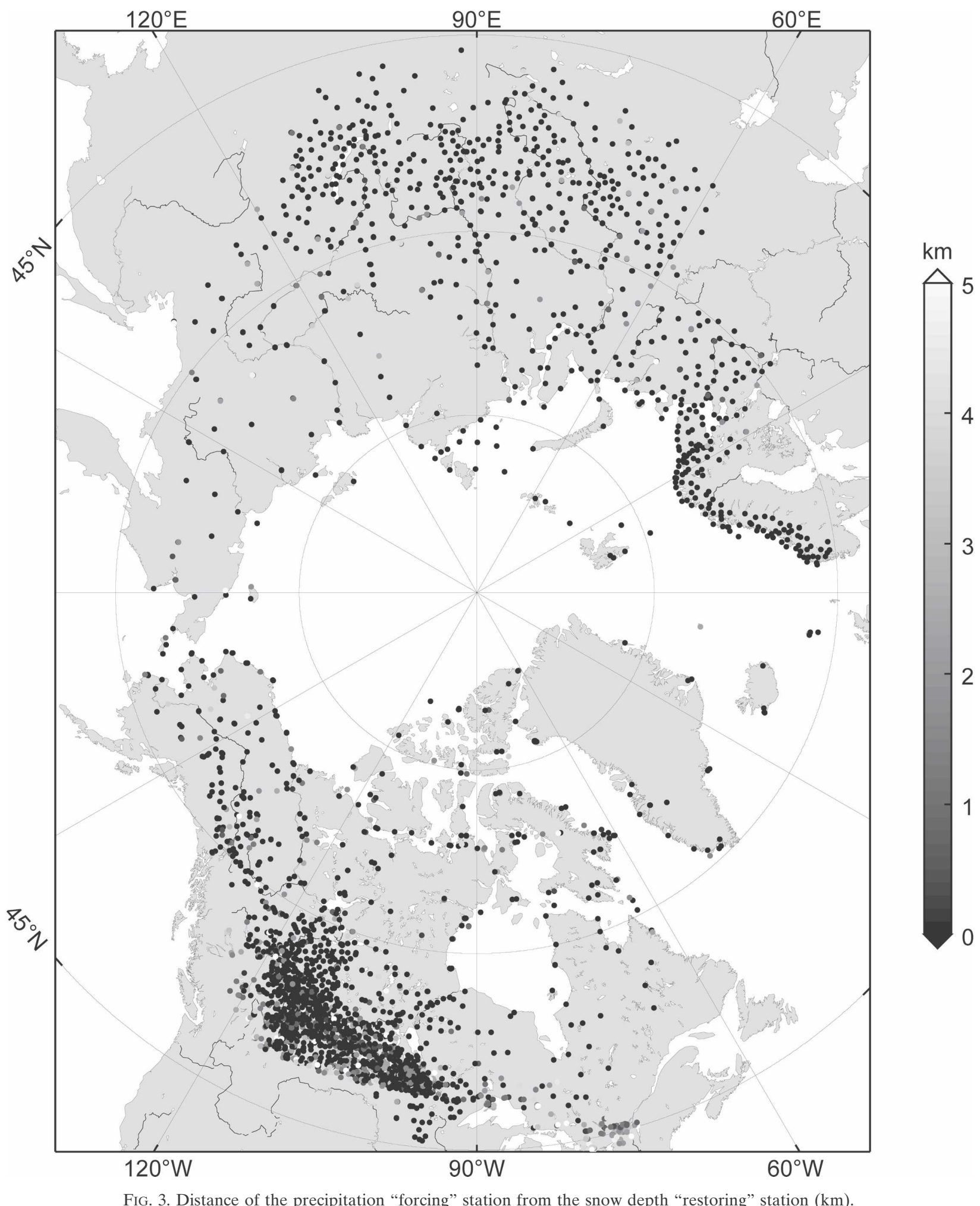




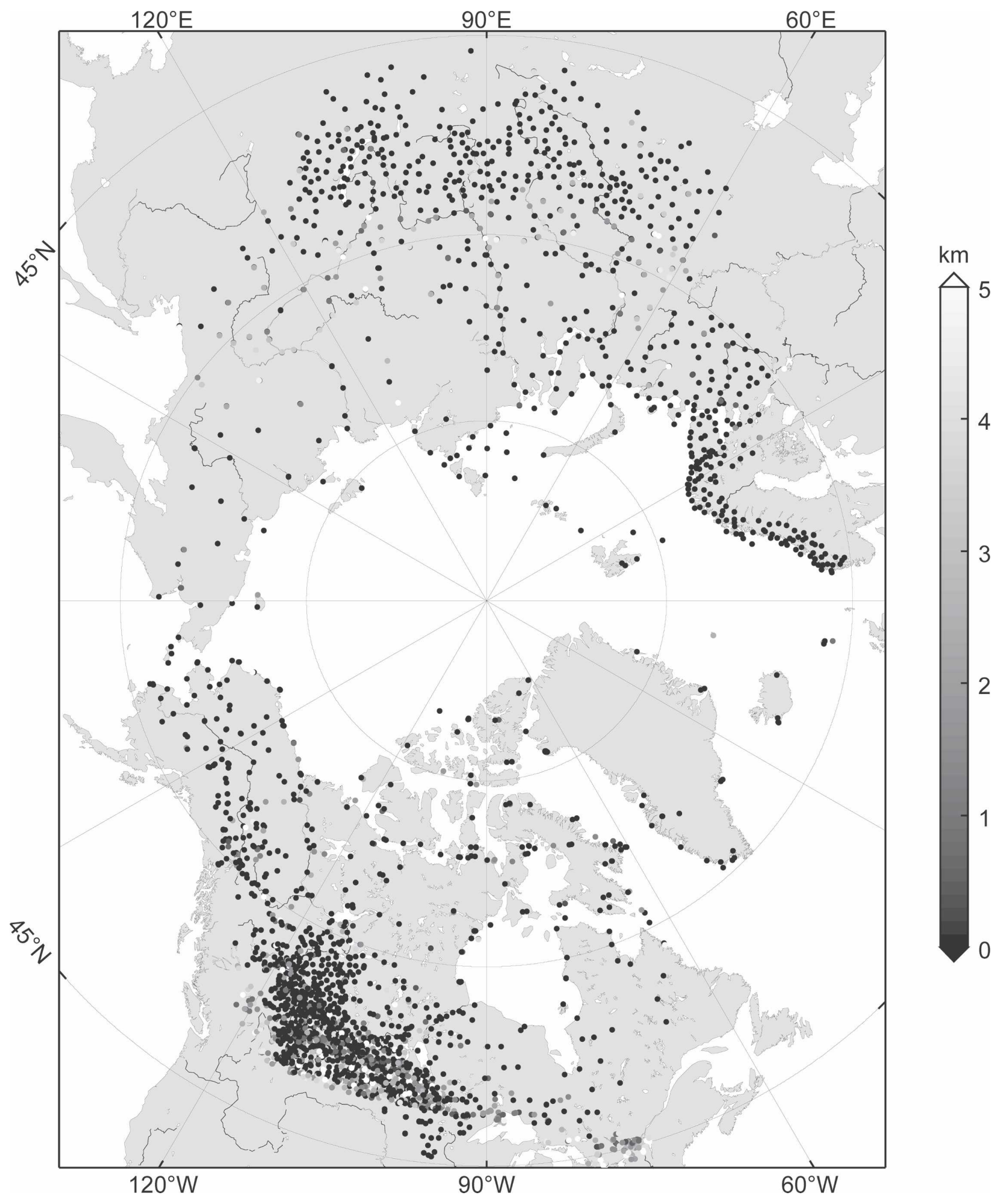

FIG. 4. Same as in Fig 3 but for the temperature. 
(positive or negative), though reconstructed snowfall is constrained to be positive. Finally, precipitation is only reconstructed between 1 October and 31 May to avoid mixed-phase precipitation summer events. While there are still such events during the reconstruction period, especially during the shoulder seasons, they impact the snowpack and cannot be discounted.

Comparisons are made between the reconstructions and Yang et al. (2005) corrected gauge data. Monthly precipitation totals were used, multiplied by the percent of precipitation that occurred as snow (these percentages are provided with the Yang et al. dataset). Comparisons were also made between the reconstructions and ERA-40 snowfall data. ERA-40 and its predecessor, the 15-yr ECMWF Re-Analysis (ERA-15), have been analyzed and compared with other products specifically for the arctic domain (Walsh et al. 1998; Cullather et al. 2000; Serreze and Hurst 2000; Bromwich et al. 2002; Genthon 2002; Serreze and Etringer 2002; Serreze et al. 2003) and have been used in polar climate studies (Betts et al. 2003; Déry and Wood 2004). Finally, the differences between the reconstructed snowfall and the gauge snowfall (gauge biases) are compared to gauge precipitation biases from Fekete et al. (1999), which are calculated from observed river discharge and a water balance model (WBM).

\section{Results at four Arctic stations}

Four stations in the arctic hydrological catchment were chosen for examining the PASR approach in depth. These locations were chosen because their records extend throughout all or most of the 60-yr period and they were also at or near test sites that were used to develop the WMO gauge corrections. These stations, Dease Lake (British Columbia) and Regina (Saskatchewan), Canada, and Barrow, Alaska, and Minot, North Dakota, vary considerably in their geography and climate. Dease Lake $\left(58.42^{\circ} \mathrm{N}, 130.00^{\circ} \mathrm{W}\right)$ is in northern British Columbia, east of Juneau, Alaska, on the Pacific-Arctic hydrological divide. The elevation of the snow station is $625 \mathrm{~m}$ above mean sea level (MSL). The station is situated in the Tanzilla Valley, in the Cassiar Mountains. Regina $\left(50.42^{\circ} \mathrm{N}, 104.62^{\circ} \mathrm{W}, 526 \mathrm{~m}\right.$ MSL) and Minot ( $\left.48.25^{\circ} \mathrm{N}, 101.28^{\circ} \mathrm{W}, 511 \mathrm{~m} \mathrm{MSL}\right)$ are both located on the flat, open North American prairie. These areas are subject to high winds for much of the winter, which transport significant amounts of blowing snow. Barrow $\left(71.30^{\circ} \mathrm{N}, 156.78^{\circ} \mathrm{W}, 3 \mathrm{~m}\right.$ MSL) has a coastal marine climate, being located on the Beaufort Sea (Arctic Ocean). These stations typify several of the important snowfall regimes in the arctic hydrologic catchment.
Figures 5 show cumulative monthly reconstructed snowfall at Dease Lake, plotted against the gauge record and the corrected gauge record. During the early part of the 1950s, significant portions of the gauge records (and therefore reconstruction forcing) are infilled with climatology. There are also months when significant portions of the temperature data or snow depth are also missing, such as in the early 1940s. This may account for the large differences between the reconstruction and the gauge record, particularly in the early part of the snow season. Starting in the late 1950s, the early season reconstructed snowfall is nearly the same as gauge estimates. During the later part of the season, the reconstructed snowfall at Dease Lake is far greater than that which was measured by the snow gauge. In other words, the observed snowpack is much deeper than a model snowpack built from observed meteorological conditions. Potential reasons for this will be discussed further in the following section. The corrected snow gauge shows even less than the raw gauge data at times, particularly during water years 1995-96, 1996-97, and 1998-99. The ERA-40 product was chosen for additional comparison because of its wide usage in the climate science community. At Dease Lake, ERA-40 snowfall is significantly less than either the gauge or the reconstructed snowfall during all years.

Figures 6 show results for Regina. This record shows significantly less reconstructed snowfall, particularly in the early part of the snow season. The corrected gauge record is generally slightly higher than the gauge record, though in 1982, it is nearly double. At Regina, there is no consistent relationship between ERA-40 and reconstructed snowfall, though it is nearly always less than the gauge snowfall.

Figures 7 show the reconstruction results for Barrow. The Barrow reconstruction shows more frozen precipitation than gauges some years and less in other years, until the 1990s, when reconstructed snowfall is generally much greater than gauge snowfall. The corrected gauge record shows a consistently higher amount of snowfall than the raw data record shows; however, there are several years (1975-76, 1976-77, 1985-86, 1999) during which extreme snowfall rates were calculated by Yang et al. (2005). These are probably unrealistic and it is unclear what the source of these errors might be as they are not associated with high monthly values of wind speed. Yang has suggested that raw daily data quality is likely to be the problem (D. Yang 2006, personal communication) and more reliable estimates from Barrow can be made from the detailed studies done separately at this station (Yang et al. 1998; Benning and Yang 2005). At Barrow, ERA-40 is sometimes 

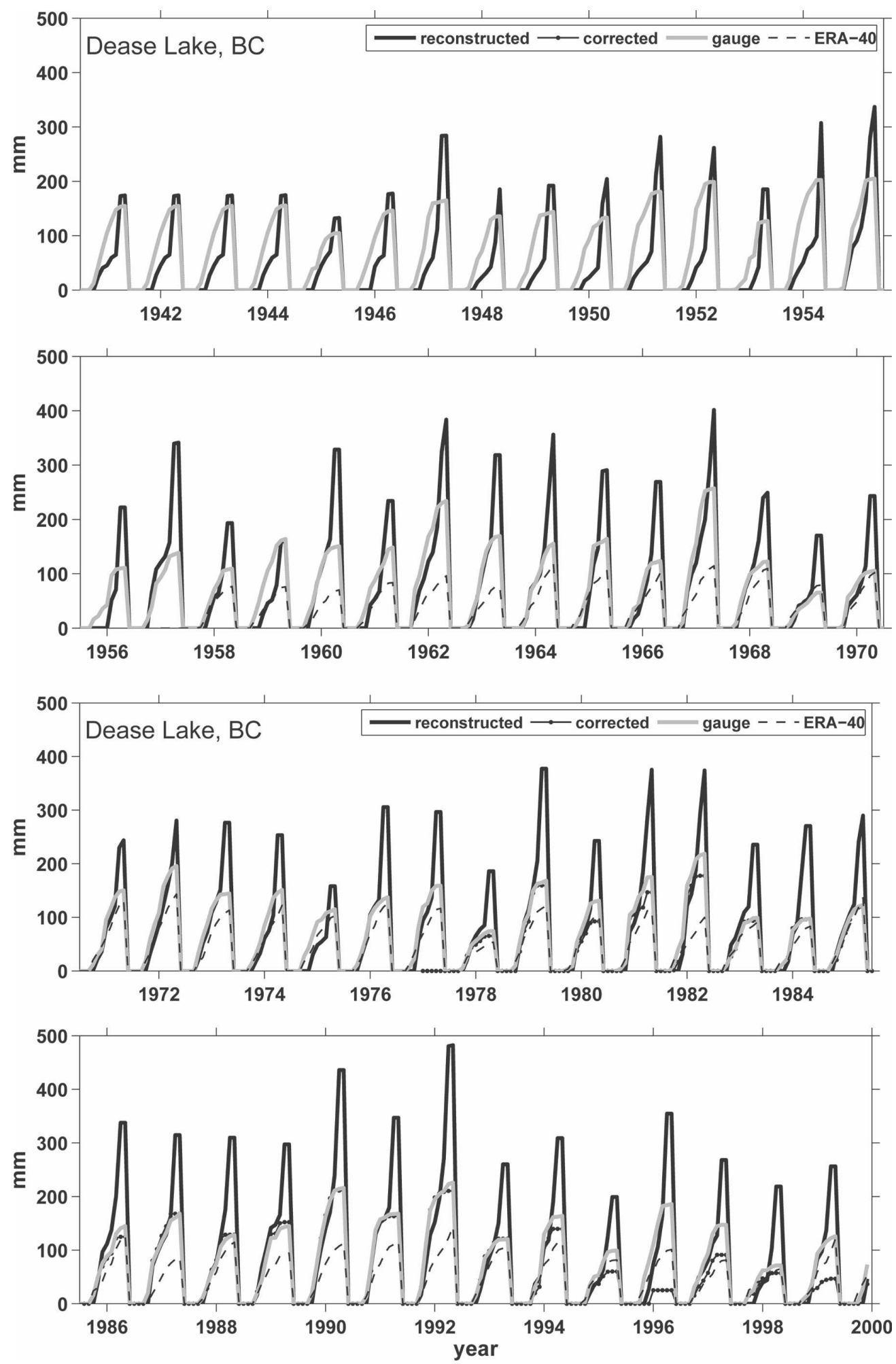

FIG. 5. Cumulative monthly reconstructed snowfall, corrected gauge snowfall (Yang et al. 2005), gauge snowfall, and ERA-40 for Dease Lake. The Yang et al. record starts in 1977 at this station. The ERA-40 data start in 1957. During some years the monthly values of the corrected gauge and gauge snowfall are nearly equal. 

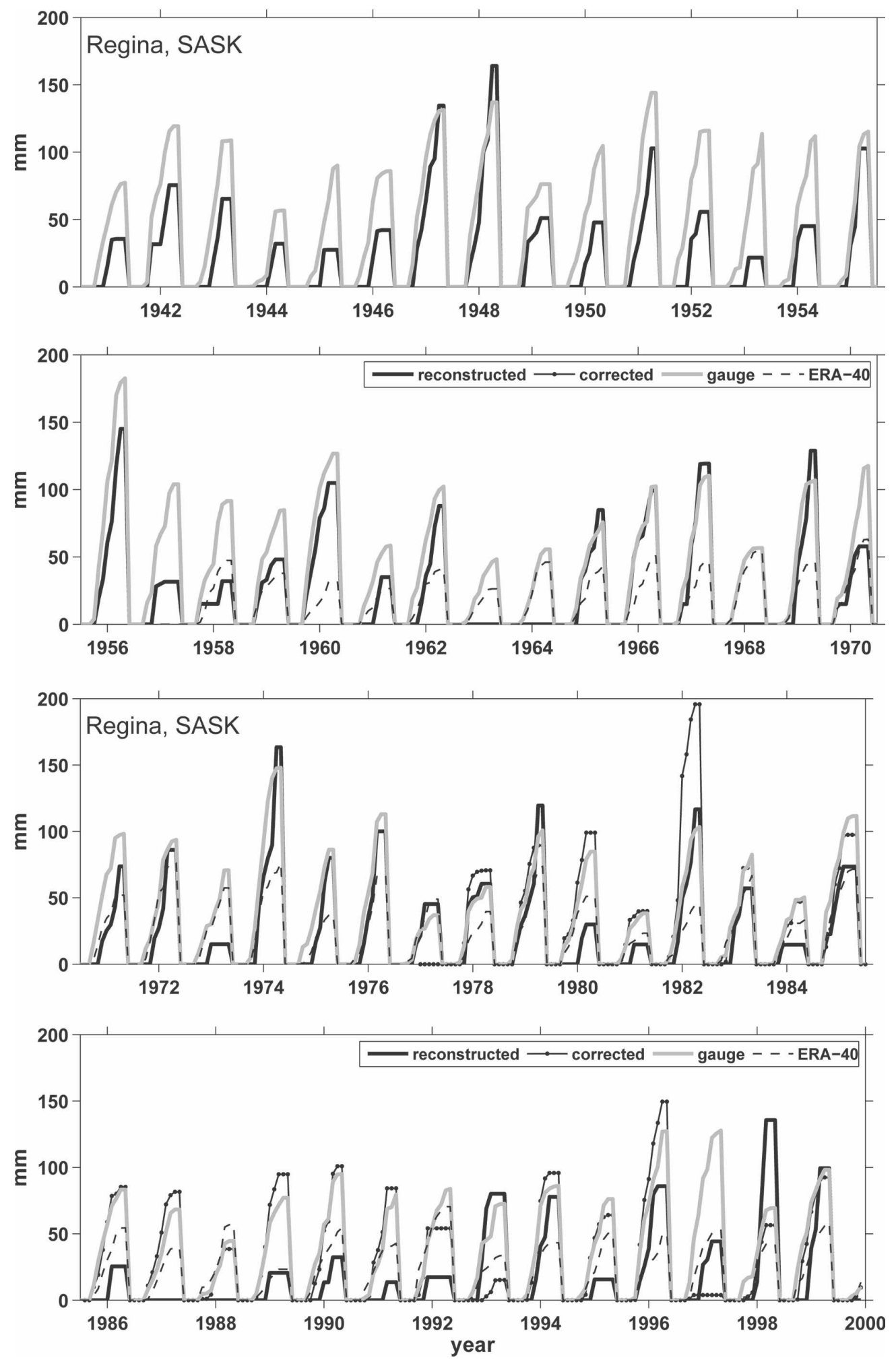

FIG. 6. Same as in Fig. 5 but for Regina. 


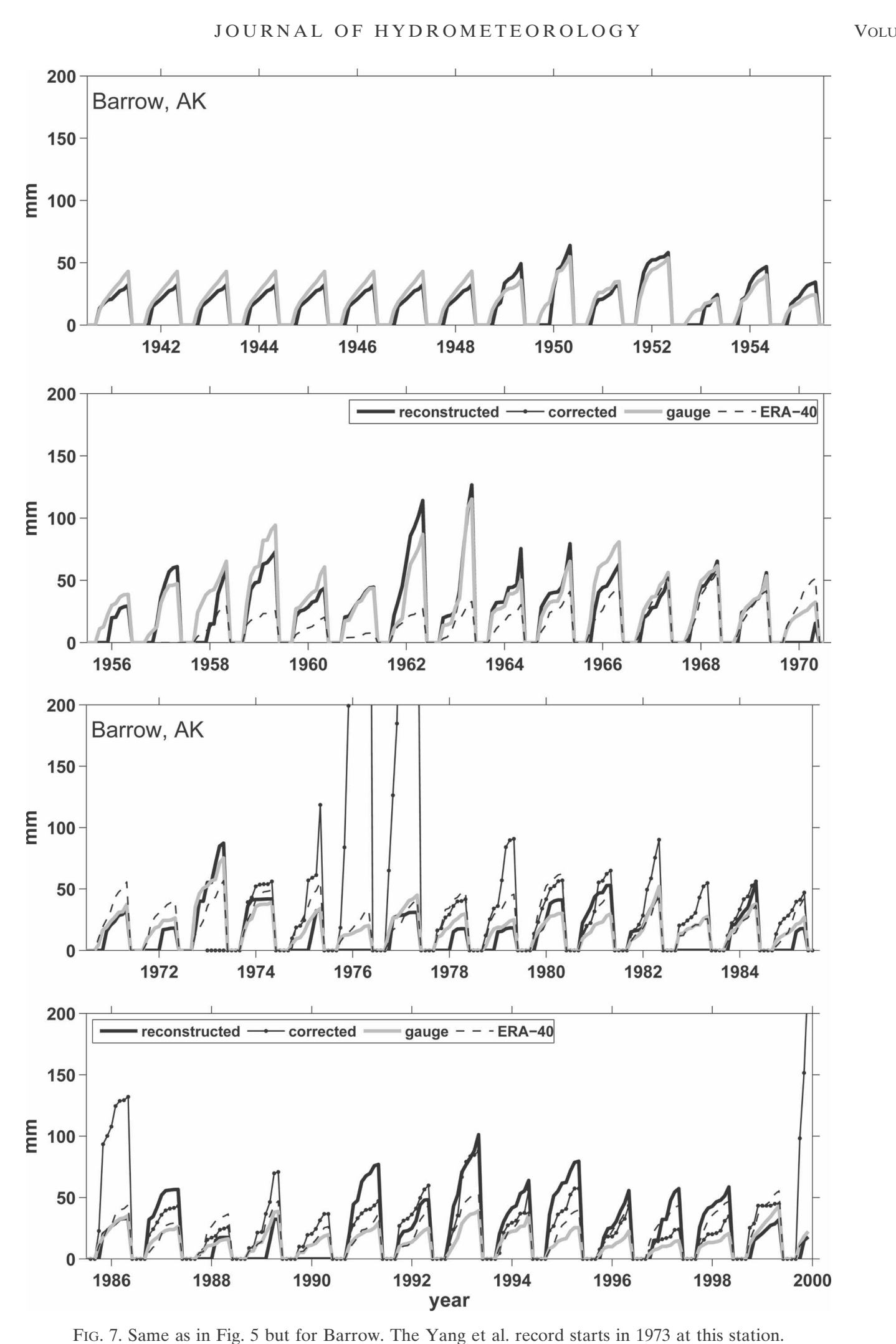


less than and sometimes greater than either the reconstructed snowfall or the gauge snowfall.

Figures 8 show the results for Minot. In general, the reconstruction is lower than the gauge precipitation, with the exception of the mid- to late 1990s. The gauge correction is accounting for overcatch some years and undercatch in others. Two years in which the gauge correction calculates $50 \%$ or more undercatch (1974$75,1983-84)$, the reconstruction is nearly identical to the gauge record. In a third year of high corrected gauge snowfall (1996-97), the total reconstructed snowfall is about $180 \mathrm{~mm}$ less than the corrected value but is still more than twice the gauge observation. The infilling climatology here produces no reconstructed precipitation. This means that the observed monthly mean climatological snow depth is much shallower than the one produced by modeling the depth with the observed SAT and precipitation. As in Regina, there is no consistent relationship between ERA-40 and reconstructed snowfall at Minot, though it is nearly always less than the gauge snowfall.

To elucidate some of the physical reasons behind the differences in reconstructed solid precipitation and solid precipitation from gauges, the nonzero daily differences (reconstructed minus gauge precipitation) were plotted against daily wind speed and mean temperature for each station in Fig. 9. The daily wind speed data are from the GLOBALSOD dataset and are only available from 1994 to 1999 . The daily mean temperatures were used for the entire period of 1940-99. There is no clear relationship between these differences and wind speed or magnitude of temperatures below about $-2^{\circ} \mathrm{C}$. Above $-2^{\circ} \mathrm{C}$, however, there appears to be a relationship between positive snowfall errors and temperature, particularly at the Dease Lake station. Evidence at the other stations for this relationship is much weaker. While the reconstruction method only calculates frozen precipitation, there appear to be a large number of rain-on-snow events at Dease Lake. As discussed in Cherry et al. (2005b), the model snowpack may not be metamorphosing accurately during rain-onsnow events; this might introduce errors into the reconstruction and is discussed further below.

There is also no significant correlation between the percentage of missing data that are in-filled with climatology and the absolute difference between the reconstruction and the gauge snowfall. The percentage of in-filling varies for each forcing/restoring parameter and between the stations. This is shown in Table 1 . Regina has the least missing data of all the stations and Minot has the most, for the period of 1940-99. Whether or not reconstructions made with in-filled data should be used for any particular application is discussed further in the following section.

In Fig. 10, cumulative snowfall climatologies are shown for each product at each test station. Months with climatological in-filling were not used to calculate these climatologies. At Dease Lake and Barrow, the annual total reconstructed snowfall is greater than the gauge snowfall and ERA-40 snowfall. However, the corrected gauge snowfall is much greater at Barrow, due in part to the extreme years mentioned above. A second corrected gauge climatology, ignoring these extreme errors, is plotted for Barrow. This climatology is still much higher than the other solid precipitation estimates. At Regina and Minot, the reconstructed snowfall is less than both the gauge and the corrected gauge records but higher than ERA-40. The potential influence of blowing snow at these sites will be discussed below.

\section{Discussion}

The reconstruction approach is an independent way to estimate snowfall. Snow depth measurements have different systematic and unsystematic biases than do gauges (Cherry et al. 2005b). Differences between the reconstructed snowfall and the gauge snowfall are not correlated with wind speed or low $\left(<-2^{\circ} \mathrm{C}\right)$ temperatures, but more positive errors seem to appear during warm temperatures $\left(>-2^{\circ} \mathrm{C}\right)$, at least at Dease Lake, when mixed precipitation and rain-on-snow events may be occurring. This method does not consistently reconstruct more or less snowfall than is captured by the gauges at each of the four test stations but is consistent with gauge precipitation biases calculated using water balance methods (Fekete et al. 1999) discussed below.

Both the corrected gauge and the reconstructed snowfall show significantly more snowfall than ERA-40 at all four stations. Serreze et al. (2005) state that "comparing (precipitation) output from reanalysis ... directly with station data is unwarranted because of large differences in spatial scale of the data." While the creation of a gridded version of PASR may show stronger correlations with the ERA-40 product, the gridding procedure can obscure certain physical processes that are apparent when examining station data. Whether or not the snow depth station data are representative of that at the scale of the grid cell will certainly vary from station to station and is not examined in Serreze et al. (2005).

Differences between the reconstruction and the gauge precipitation do not correlate with wind speed because both neglect snow transported away by wind. For gauges, however, that snow is never measured (high wind causes high undercatch) and this is one rea- 

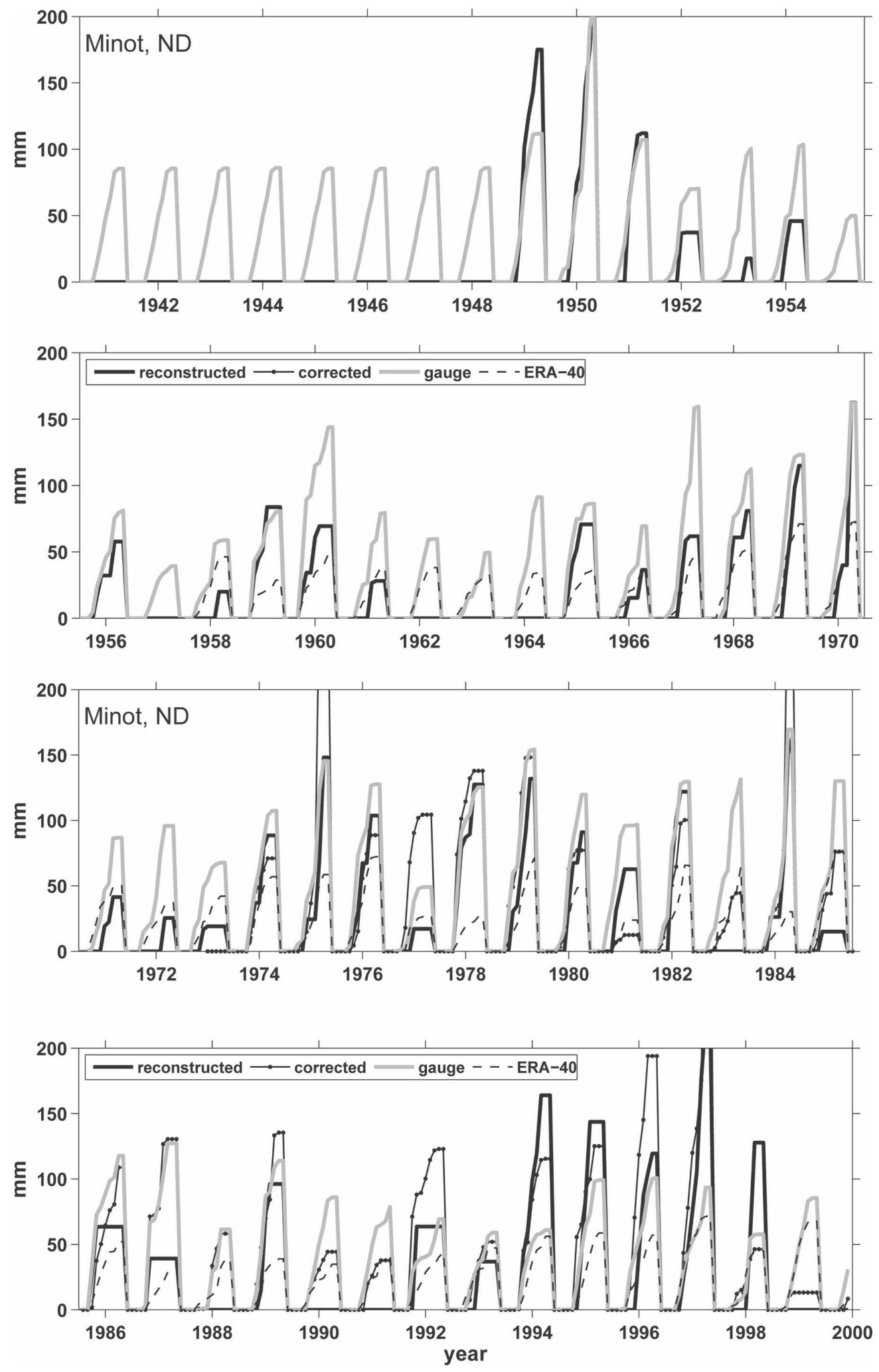

FIG. 8. Same as in Fig. 5 but for Minot. The Yang et al. record starts in 1973 at this station. 

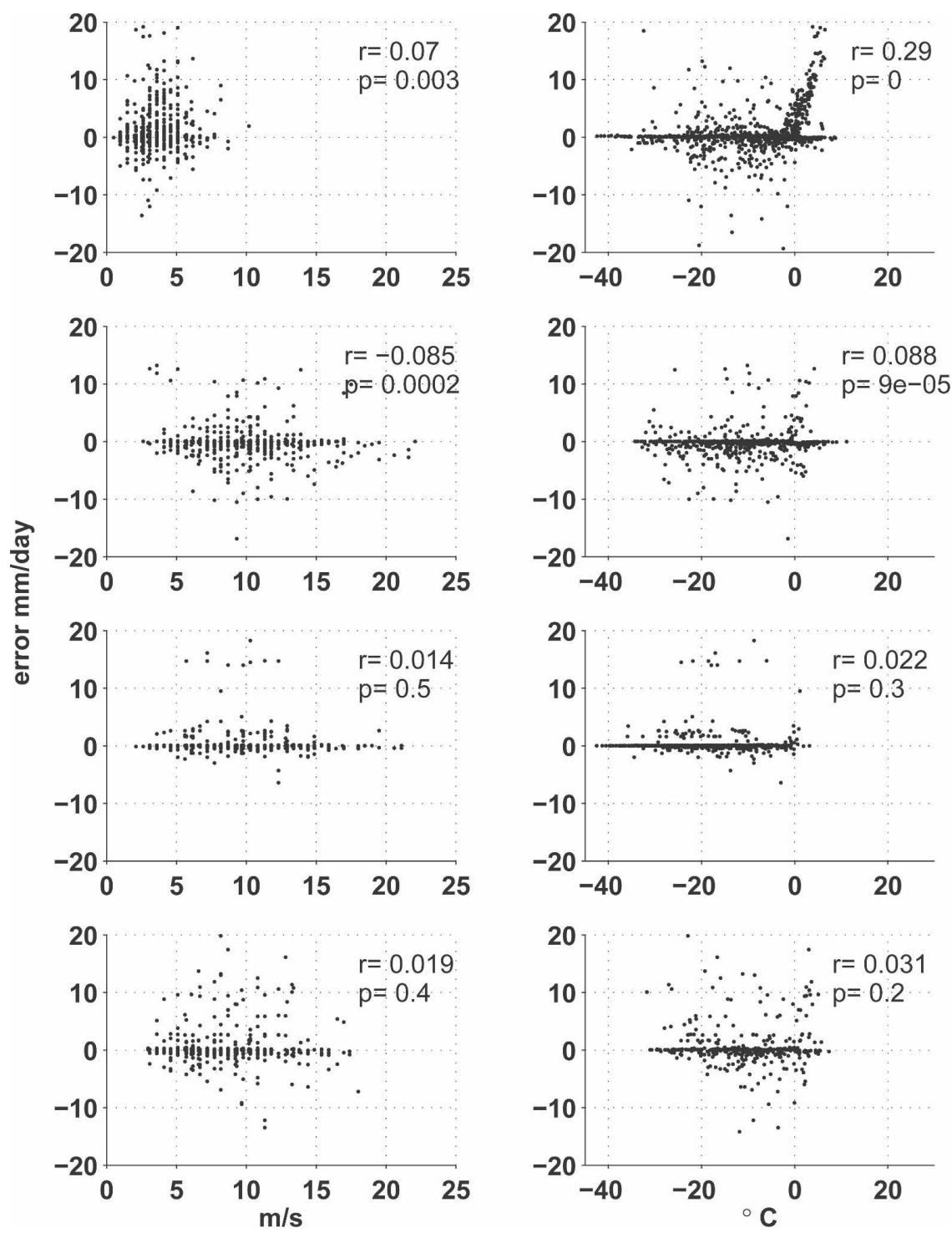

FIG. 9. Difference between daily reconstructed snowfall and (uncorrected) gauge snowfall vs wind speed and temperature for four test stations: (left) wind speed and (right) temperature. (top to bottom) Stations are Dease Lake, Regina, Barrow, and Minot.

son why corrections have been developed. For reconstructed snowfall, the snowfall is counted, but not where it fell. It gets counted where it ended up, because it is captured in the snow depth measurement in the deposition area. However, this may be the quantity that is most relevant for studies of large-scale hydroclimatology. Blown snow contributes to runoff in the location where it is deposited. Snow that does not sublimate during the transport will sublimate or melt in the deposition region. In the case of the North American prairies, some blown snow is probably transported out of the region.

The reconstruction climatologies at four test stations
(Fig. 10) were qualitatively compared to estimated gauge biases from Fekete et al. (1999). Figure 11, reproduced with permission from Fekete et al. (1999), shows the global gauge biases determined by the water balance approach in that study. The correction coefficient is the amount by which runoff output from their water balance model forced with gauge precipitation must be multiplied to get observed runoff. This can be written as

$$
R_{\mathrm{obs}}=\xi R_{\mathrm{wbm}},
$$

where $R_{\text {obs }}$ is the "observed" runoff, $\xi$ is the correction coefficient, and $R_{\mathrm{wbm}}$ is the runoff produced by the 
TABLE 1. Percentage of missing daily data from 1 Jan 1940 to 31 Dec 1999 for the four test stations.

\begin{tabular}{|c|c|c|c|c|}
\hline & $\begin{array}{l}\text { Dease } \\
\text { Lake }\end{array}$ & Regina & Barrow & Minot \\
\hline Precipitation & 9.5779 & 0.009126 & 17.4994 & 19.489 \\
\hline $\begin{array}{l}\text { Snow } \\
\text { depth }\end{array}$ & 12.982 & 1.8435 & 17.6363 & 19.48 \\
\hline $\begin{array}{l}\text { Temperature } \\
\max \end{array}$ & 9.6509 & 0.073009 & 18.9642 & 19.48 \\
\hline $\begin{array}{l}\text { Temperature } \\
\text { min }\end{array}$ & 9.6555 & 0.15514 & 20.2647 & 19.48 \\
\hline
\end{tabular}

model forced with gauge precipitation. This is a simplified explanation of what was done in Fekete et al. (1999). What they call $R_{\text {obs }}$ has actually been interpolated from the observations thought to have the lowest errors and topographic information, modeled river routing, etc. While comparisons for exact station locations are avoided because of the low spatial resolution of the WBM approach, this figure shows gauge biases with sizable undercatch $(\xi>1)$ in the Arctic in general, modest undercatch along the Canadian and American Rocky Mountains, and apparent overcatch on the North American prairies $(\xi<1)$. This is consistent with the PASR test results at the four test stations. Reasons for the apparent overcatch biases on the prairies most likely relate to the transport and divergence of blowing snow.

Figure 12 shows histograms of daily maximum sustained wind speed for the four test sites from 1994 to 1999. Dease Lake is considerably less windy than the other three sites and this is where the PASR method reconstructs the most snow over the corrected gauge. At approximately $10 \mathrm{~m} \mathrm{~s}^{-1}$, small amounts of snow can be transported by wind, while speeds of $20 \mathrm{~m} \mathrm{~s}^{-1}$ are associated with considerable amounts of blowing snow (Arya 2001). Dease Lake has few days above $10 \mathrm{~m} \mathrm{~s}^{-1}$, while Barrow, Regina, and Minot all have a significant number of these events. This is consistent with blowing snow climatologies from Déry and Yau (1999). The likelihood of blowing snow divergence or convergence at a station clearly affects how the snowfall reconstruction should be interpreted. The reconstructions capture snow that was deposited in a region because it appears as a positive snow depth change. Negative depth changes are used to readjust the initial guess of daily precipitation but are limited by the constraint that daily precipitation is zero or positive.

The present development study has made it clear that to interpret the PASR product one needs to include information about daily wind speed, where and when it is available, as well as wind convergence and diver-
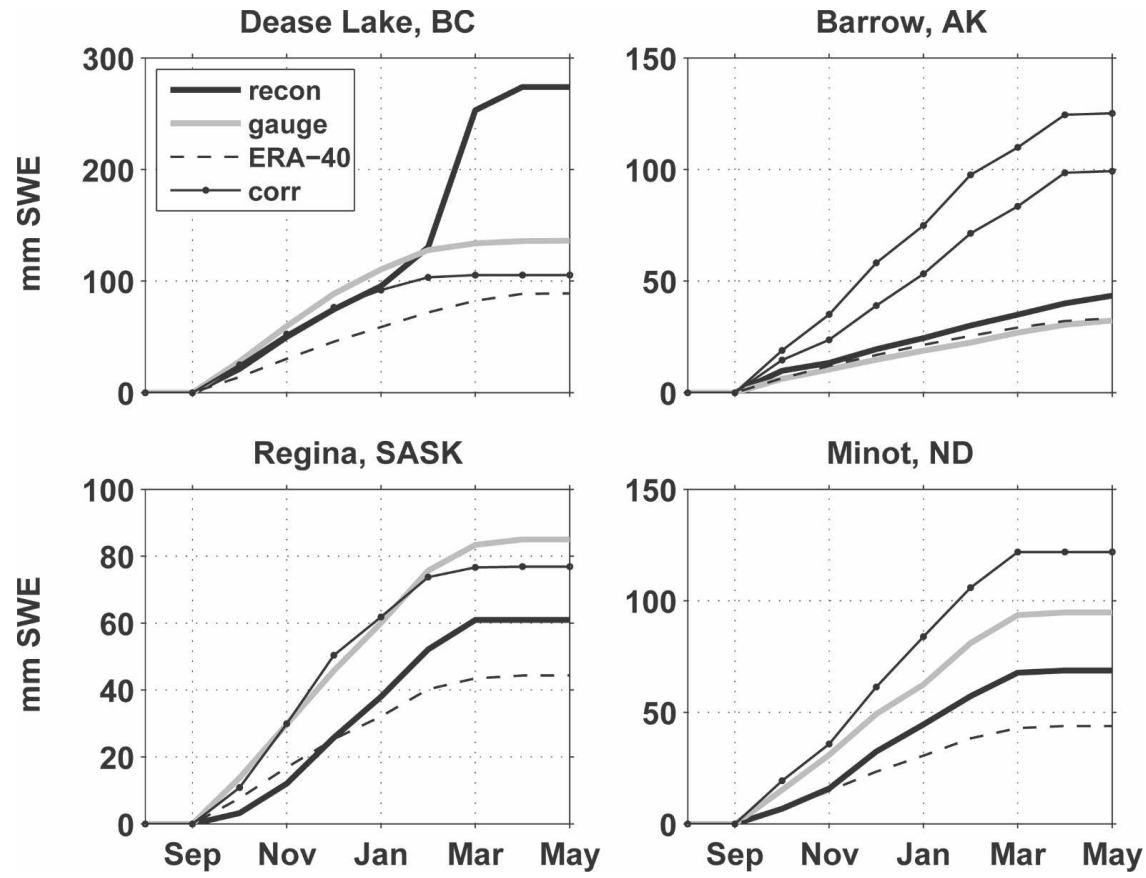

FIG. 10. Cumulative annual snowfall climatologies for four test stations using four different datasets: the reconstruction, raw gauge data, corrected gauged data from Yang et al. (2005), and ERA-40. For Barrow, two different climatologies are plotted for the corrected gauge dataset: one calculated without the extreme errors of 1975-77 and 1999 (the lower curve) and one calculated with the errors (the upper curve). 


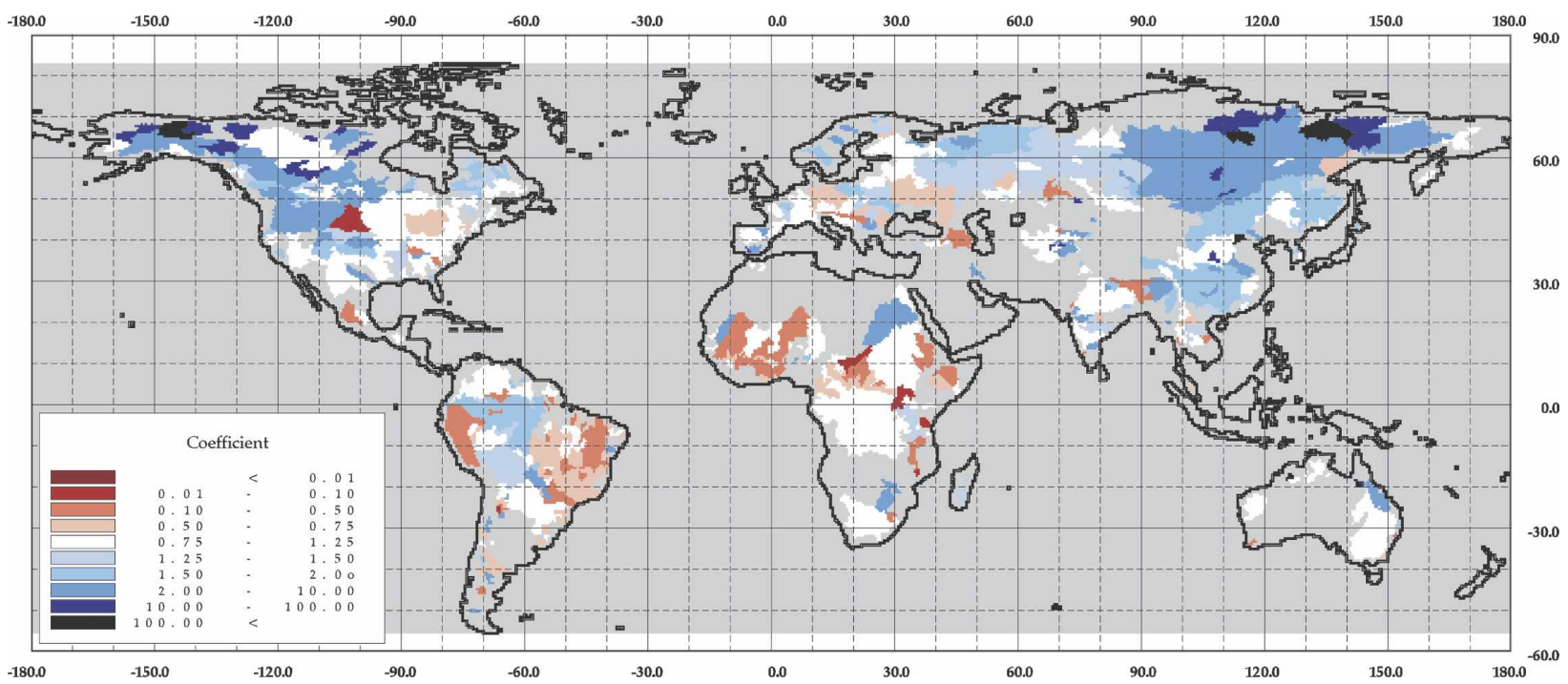

FIG. 11. Runoff correction coefficients from the WBM, reproduced from Fekete et al. (1999). This shows the bias in gauge precipitation compared to measured runoff and a balanced water budget. Coefficients greater than one (blue to black) represent gauge undercatch while coefficients less than one (pink to red) represent gauge overcatch.

gence. Because of the high winds, both Barrow and the Prairie stations are expected to show strong gauge undercatch biases. Statistical gauge corrections (based on wind speed) show significantly more snowfall at Barrow and Minot than the raw gauge data. However, the re- construction climatologies in Fig. 10 show modest gauge undercatch for Barrow but significant overcatch for the Prairies-both under high wind conditionssuggesting blowing snow convergence in Barrow and divergence on the prairies. A user must have some
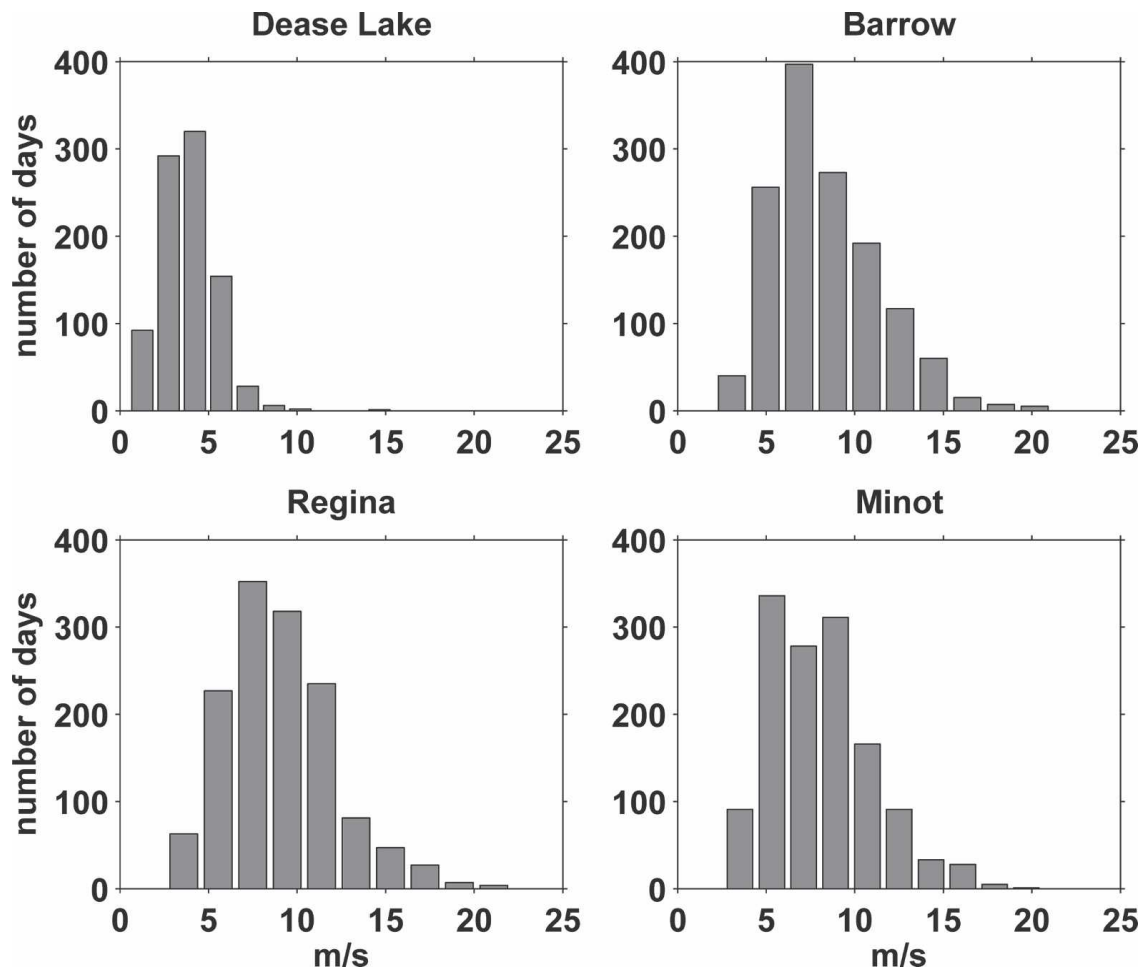

FIG. 12. Histograms of maximum sustained wind speed at four PASR test sites. These daily data are from the GLOBALSOD dataset, available for the period of 1994-99. 
knowledge of large-scale patterns of snow transport if he or she is concerned about the source region of snow. Déry and Yau (1999, 2002) show climatological estimates of likely regions of blowing snow and its divergence.

Treatment of missing data is another issue that affects all climate datasets, including the PASR. Because the PASR approach is model-based, forcing and restoring data must be in-filled to keep the model running continuously over the snow season. The simple correlation tests between the error and missing data percentage described above do not fully capture the impact of data in-filling on the snowfall reconstruction. For example, several days of consecutive in-filling with climatology for snow depth is likely to have a much larger impact than occasional in-filling of temperature forcing.

Finally, trace events $(\leq 0.2 \mathrm{~cm})$ are another challenge to estimating arctic precipitation. While the model has difficulty simulating trace snowfall events on bare ground (especially if snow melts before depth is observed), it does capture trace events well once the snow is more than $13 \mathrm{~mm}$ deep. This is, of course, provided that the trace amount is measurable as an increase in snow depth. The method cannot account for trace amounts smaller than the precision of the depth measurement device unless multiple trace events aggregate to a measurable amount of snow.

There are few arctic stations where the kind of proof of concept done at RCEW could be repeated. It is possible to estimate the error of the RCEW reconstruction using hourly snow water equivalent from a snow pillow, which does not have the same systematic undercatch biases as a gauge. This proof of concept was meant to inform the larger pan-arctic reconstruction, not to claim that the unsystematic biases at this site are the same as those at every arctic site. However, snow depth measurements are taken along a transect and averaged, taken from a permanent graduated stake, or simply made in the same general area each day. There are objective reasons to think that snow depth measurements may be less systematically biased than gauge observations, simply because the gauge is a large, disruptive device with design shortcomings and subject to mechanical errors. Regardless, snow depth varies significantly on all scales (Neumann et al. 2006), particularly with topography, and both measurements have unsystematic biases associated with siting. These potential siting biases are neither estimated nor overcome by the method used to develop the PASR dataset.

\section{Conclusions}

The present development study describes a new approach for estimating arctic solid precipitation and ex- plores the product's physical underpinnings, interpretation, and potential robustness. Advantages of this approach include that 1 ) the assimilation of snow depth observations captures blowing snow where it is deposited and 2) the modeling approach takes into account physical snowpack evolution. These advantages suggest that the PASR product could be a valuable alternative to statistical gauge corrections.

The dynamical snow model, within the NSIPP CLSM, is the strongest asset of the reconstruction approach. The meteorological forcing with temperature helps determine the evolution of the snowpack. Forcing with gauge precipitation creates an initial estimate of the precipitation input and the resulting impact on the growth, compaction, ripening, or ablation of the snowpack. The final restoring to observed snow depth at the end of the time step corrects the initial estimate of snowfall. This is quite different than a statistical correction of snowfall from a standard gauge, based on its past catch relationship with a "true" gauge, as a function of meteorological parameters.

Future work by the investigators includes comparison of the full pan-arctic domain of the PASR with other arctic precipitation estimates (and implications of our new estimate for the arctic freshwater budget), distribution of the full PASR product, and further development of the PASR product using additional meteorological observations as forcings. The development of the PASR described in the present study has provided insight into the physical processes that may impact the robustness of the reconstruction approach. Providing information about the potential for mixed-phase precipitation, blowing snow, and missing forcing data with the PASR will allow the user to choose reconstruction data that are appropriate for his or her application.

Finally, results from the PASR may influence the design of future observation systems. As shown in Fig. 2 , the number of precipitation gauges in the Arctic has dropped dramatically since the 1980s. The same is true of temperature, and especially of snow depth, and runoff. This apparent trend is due in part to the fact that observations can take many years to become available to researchers. On the other hand, the number of stations operating has also declined dramatically in Russia and Canada, and to a lesser extent in the United States (Vörösmarty et al. 2001). The results here suggest that using depth to reconstruct snowfall is a viable alternative to corrected gauges. The implication for future station design is that unmanned precipitation gauges might be replaced by automatic snow depth sensors. Some automated systems like the SNOTEL network in the western United States have already begun to add ultrasonic depth sensors to the existing station instru- 
mentation (see online at http://www.wcc.nrcs.usda.gov/ snow/snotel-depth.html).

The Arctic is changing quickly. Most arctic research is related to snowfall in someway or another. The arctic freshwater budget is not balanced by direct observations of precipitation (Vörösmarty et al. 2001); we need better estimates of snowfall. The reconstruction approach is an alternative to corrected gauge records, is not subject to the same biases, and has a flexible, model-based framework in which to develop further.

Acknowledgments. The authors wish to thank the NASA Earth System Science Fellowship program, Columbia University's Department of Earth and Environmental Science, and the Lamont-Doherty Earth Observatory (LDEO) Climate Center, and the Arctic Region Supercomputing Center for support of Jessie Cherry's contribution. Bruno Tremblay was supported by NSF OPP-0520496 and OPP-0230264. Gavin Gong was supported by NOAA's OGP. The participation of Marc Stieglitz has been funded through support from NSF grants from the Office of Polar Programs (OPP002369), from the division of Environmental Biology (Arctic LTER Project), from an NSF Cooperative Agreement (OPP-0002239), as well as by the NASA Seasonal-to-Interannual Prediction Project at Goddard Space Flight Center, NASA's Global Modeling and Analysis Program under RTOP 622-24-47, and NSF Biocomplexity Grant 0439620. Stephen Déry is supported by the Canada Research Chair program of the Government of Canada. The authors wish to thank Peter Schlosser, Andrew Charlton, Jennifer Francis, and three anonymous reviewers for their comments.

\section{REFERENCES}

ACIA, Eds., 2004: Arctic Climate Impact Assessment. Cambridge University Press, 1042 pp.

Adam, J. C., and D. P. Lettenmaier, 2003: Adjustment of global gridded precipitation for systematic bias. J. Geophys. Res., 108, 4257, doi:10.1029/2002JD002499.

Arkin, P. A., and P. E. Ardanuy, 1989: Estimating climatic-scale precipitation from space: A review. J. Climate, 2, 1229-1238.

Arya, S. P., 2001: Introduction to Micrometeorology. 2d ed. Academic Press, 420 pp.

Barnett, T. P., L. Dumenil, U. Schlese, E. Roeckner, and M. Latif, 1989: The effect of Eurasian snow cover on regional and global climate variations. J. Atmos. Sci., 46, 661-685.

— J. C. Adam, and D. P. Lettenmaier, 2005: Potential impacts of a warming climate on water availability in snow-dominated regions. Nature, 438, 303-309.

Benning, J., and D. Yang, 2005: Adjustment of daily precipitation data at Barrow and Nome Alaska for 1995-2001. Arct. Antarct. Alp. Res., 37 (3), 267-283.

Berezovskaya, S., D. Yang, and D. L. Kane, 2004: Compatibility analysis of precipitation and runoff trends over the large $\mathrm{Si}$ - berian watersheds. Geophys. Res. Lett., 31, L21502, doi:10.1029/2004GL021277.

Betts, A. K., J. H. Ball, and P. Viterbo, 2003: Water and energy budgets for the Mackenzie River basins from ERA-40. J. Hydrometeor., 4, 1194-1211.

Beven, K. J., and M. J. Kirkby, 1979: A physically-based variable contributing area model of basin hydrology. J. Hydrol. Sci., 24, 43-69.

Bromwich, D. H., S.-H. Wang, and A. J. Monaghan, 2002: ERA40 representation of the arctic atmospheric moisture budget. ECMWF ERA-40 Project Report Series 3, 12 pp.

Chapin, F.S., III, and Coauthors, 2005: Role of land-surface changes in Arctic summer warming. Science, 310, 657-660.

Chapman, W. L., and J. E. Walsh, 1993: Recent variations of sea ice and air temperature in high latitudes. Bull. Amer. Meteor. Soc., 74, 33-47.

Cherry, J. E., H. M. Cullen, M. Visbeck, A. Small, and C. Uvo, 2005a: Impacts of the North Atlantic oscillation on Scandinavian hydropower production and energy markets. Water Resour. Manage., 19, 673-691.

_ L. B. Tremblay, S. J. Déry, and M. Stieglitz, 2005b: Reconstructing solid precipitation from snow depth measurements and a land surface model. Water Resour. Res., 41, W09401, doi:10.1029/2005WR003965.

Cohen, J., and D. Entekhabi, 2001: The influence of snow cover on Northern Hemisphere climate variability. Atmos.-Ocean, 39, 35-53.

Cullather, R. I., D. H. Bromwich, and M. C. Serreze, 2000: The atmospheric hydrologic cycle over the Arctic basin from reanalyses. Part I: Comparison with observations and previous studies. J. Climate, 13, 923-937.

Dai, A., F. Giorgi, and K. E. Trenberth, 1999: Observed and model-simulated diurnal cycles of precipitation over the contiguous United States. J. Geophys. Res., 104, 6377-6402.

Déry, S. J., and M. K. Yau, 1999: A climatology of adverse wintertype weather events. J. Geophys. Res., 104 (D14), $16657-$ 16672.

— , and — 2002: Large-scale mass balance effects of blowing snow and surface sublimation. J. Geophys. Res., 107, 4679, doi:10.1029/2001JD001251.

— , and E. F. Wood, 2004: Teleconnection between the Arctic Oscillation and Hudson Bay river discharge. Geophys. Res. Lett., 31, L18205, doi:10.1029/2004GL020729.

— W. T. Crow, M. Stieglitz, and E. F. Wood, 2004: Modeling snowcover heterogeneity over complex Arctic terrain for regional and global climate models. J. Hydrometeor., 5, 33-48.

— , V. V. Salomonson, M. Stieglitz, D. K. Hall, and I. Appel, 2005a: An approach to using snow areal depletion curves inferred from MODIS and its application to land surface modelling in Alaska. Hydrol. Processes, 19, 2755-2774.

—, M. Stieglitz, A. K. Rennermalm, and E. F. Wood, 2005b: The water budget of the Kuparuk River basin, Alaska. $J$. Hydrometeor., 6, 633-655.

Ducharne, A., R. D. Koster, M. J. Suarez, M. Stieglitz, and P. Kumar, 2000: A catchment-based approach to modeling land surface processes in a general circulation model. 2. Parameter estimation and model demonstration. J. Geophys. Res., 105 (D20), 24 823-24 838.

ECMWF, cited 2003: ECMWF Reanalysis-40. [Available online at http://www.ecmwf.int/research/era/.]

Environment Canada, 2000: Daily Snow Depth and Snow Water Equivalent. Downsview, ON, CD-ROM. 
_ 2002: Canadian Daily Climate Data. Downsview, ON, CDROM.

Fekete, B. M., C. J. Vörösmarty, and W. Grabs, 1999: Global, composite runoff fields based on observed river discharge and simulated water balances. WMO Global Runoff Data Center Rep. 22, Koblenz, Germany, 36 pp.

,-- J. O. Roads, and C. J. Willmott, 2004: Uncertainties in precipitation and their impacts on runoff estimates. $\mathrm{J}$. Climate, 17, 294-304

Genthon, C., 2002: Climate and surface mass balance of the Polar ice sheets in ERA-40/ERA15. ECMWF ERA-40 Project Report Series 3, $18 \mathrm{pp}$.

Gong, G., D. Entekhabi, and J. Cohen, 2002: A large-ensemble model study of the wintertime $\mathrm{AO} / \mathrm{NAO}$ and the role of interannual snow perturbations. J. Climate, 15, 3488-3499.

$\ldots$, _ and _ 2003a: Relative impacts of Siberian and North American snow anomalies on the Northern Hemisphere mode. Geophys. Res. Lett., 30, 1848, doi:10.1029/ 2003 GL017749.

$\_, \ldots$, and $\_$2003b: Modeled Northern Hemisphere winter climate response to realistic Siberian snow anomalies. $J$. Climate, 16, 3917-3931.

,,--- , and D. A. Robinson, 2004: Sensitivity of atmospheric response to modeled snow anomaly characteristics. $J$ Geophys. Res., 109, D06107, doi:10.1029/2003JD004160.

Goodison, B. E., P. Y. T. Louie, and D. Yang, 1998: WMO solid precipitation intercomparison. Final Rep. WMO/TD-872, 212 pp.

Grab, S., 2005: Aspects of the geomorphology, genesis and environmental significance of earth hummocks (thufur, pounus): Miniature cryogenic mounds. Prog. Phys. Geogr., 29 (2), 139155.

Groisman, P. Y., 1998: National Climatic Data Center data documentation for TD-9816, Canadian Monthly Precipitation. NCDC, CD-ROM.

_ , V. V. Koknaeva, T. A. Belokrylova, and T. R. Karl, 1991: Overcoming biases of precipitation: A history of the U.S.S.R. experience. Bull. Amer. Meteor. Soc., 72, 1725-1733.

_ , T. R. Karl, and R. W. Knight, 1994: Observed impact of snow cover on the heat-balance and the rise of continental spring temperatures. Science, 263, 198-200.

Hagemann, S., K. Arpe, and L. Bengtsson, 2005: Validation of the hydrological cycle of ERA-40. ERA-40 Project Report Series 24, 46 pp. [Available online at http://www.ecmwf.int/ publications/library/do/references/show?id=86720.]

Hansen, J. E., G. Russel, D. Rind, P. H. Stone, A. A. Lacis, S. Lebedeff, R. Ruedy, and L. Travis, 1983: Efficient three dimensional global models for climate studies: Models I and II. Mon. Wea. Rev., 111, 609-662.

Houghton, J. T., Y. Ding, D. J. Griggs, M. Noguer, P. J. van der Linden, X. Dai, K. Maskell, and C. A. Johnson, Eds., 2001: Climate Change 2001: The Scientific Basis. Cambridge University Press, $881 \mathrm{pp}$.

Huffman, G. J., R. F. Adler, B. R. Rudolf, U. Schneider, and P. R. Keehn, 1997: The Global Precipitation Climatology Project (GPCP) combined precipitation dataset. Bull. Amer. Meteor. Soc., 78, 5-20.

Hulme, M., and M. New, 1997: Dependence of large-scale precipitation climatologies on temporal and spatial sampling. $J$. Climate, 10, 1099-1113.

Kalnay, E., 2003: Atmospheric Modeling, Data Assimilation and Predictability. Cambridge University Press, 341 pp.
— - and Coauthors, 1996: The NCEP/NCAR 40-Year Reanalysis Project. Bull. Amer. Meteor. Soc., 77, 437-471.

Koster, R. D., M. J. Suarez, A. Ducharne, M. Stieglitz, and P. Kumar, 2000: A catchment-based approach to modeling land surface processes in a general circulation model 1. Model structure. J. Geophys. Res., 105 (D20), 24 809-24 822.

Lammers, R. B., and A. I. Shiklomanov, 2000: R-ArcticNET: A regional, electronic, hydrographic data network for the Arctic Region. Water Systems Analysis Group, University of New Hampshire. [Available online at http://www.rarcticnet.sr.unh.edu/v3.0/.]

C. J. Vörösmarty, B. M. Fekete, and B. J. Peterson, 2001: Assessment of contemporary Arctic river runoff based on observational discharge records. J. Geophys. Res., 106 (D4), 3321-3334.

Legates, D. R., and C. J. Willmott, 1990: Mean seasonal and spatial variability in gauge-corrected, global precipitation. Int. J. Climatol., 10, 111-127.

Lynch-Stieglitz, M., 1994: The development and validation of a simple snow model for the GISS GCM. J. Climate, 7, 18421855

Mackay, J. R., 1987: Some mechanical aspects of pingo growth and failure, Western Arctic Coast, Canada. Can. J. Earth Sci., 24, 1108-1119.

Marshall, J. S., and K. L. Gunn, 1952: Measurement of snow parameters by radar. J. Meteor., 9, 322-327.

McClelland, J. W., R. M. Holmes, B. J. Peterson, and M. Stieglitz, 2004: Increasing river discharge in the Eurasian Arctic: Consideration of dams, permafrost thaw, and fires as potential agents of change. J. Geophys. Res., 109, D18102, doi:10.1029/ 2004JD004583.

Mekis, E., and W. D. Hogg, 1999: Rehabilitation and analysis of Canadian daily precipitation time series. Atmos.-Ocean, 37 (1), 53-85.

Morison, J., and Coauthors, Eds., 2001: SEARCH: Study of Environmental Arctic Change. Polar Science Center Science Plan, Applied Physics Laboratory, University of Washington, $89 \mathrm{pp}$.

Neumann, N., C. Derksen, C. Smith, and B. Goodison, 2006: Characterizing local scale snow cover using point measurements during the winter season. Atmos.-Ocean, 44 (3), $257-$ 269

NOAA/NCDC, cited 1998: First order summary of the day. [Available online at http://iridl.ldeo.columbia.edu/SOURCES/. NOAA/.NCDC/.DAILY/.FSOD/.]

— online at http://iridl.ldeo.columbia.edu/SOURCES/. NOAA/.NCDC/.GDCN/.]

, cited 2004: Global historical climatology network, v.1. [Available online at http://iridl.ldeo.columbia.edu/ SOURCES/.NOAA/.NCDC/.GHCN_Daily/.version1/.]

, cited 2005: Global summary of the day. [Available online at http://iridl.ldeo.columbia.edu/SOURCES/.NOAA/.NCDC/ .DAILY/.GLOBALSOD/.]

NOAA/NGDC, cited 1993: ETOPO5 global relief. [Available online at http://iridl.ldeo.columbia.edu/SOURCES/. WORLDBATH/.]

NSIDC, 1999: Historical Soviet daily snow depth - version 2.0. CD-ROM

Peterson, B. J., R. M. Holmes, J. W. McClelland, C. J. Vorosmarty, R. B. Lammers, A. I. Shiklomanov, I. A. Shiklomanov, and S. Rahmstorf, 2002: Increasing river discharge to the Arctic Ocean. Science, 298, 2171-2173. 
Rind, D., C. Rosenzweig, and M. Stieglitz, 1997: The role of moisture transport between ground and atmosphere in global change. Annu. Rev. Energy Environ., 22, 47-74.

Serreze, M. C., and C. M. Hurst, 2000: Representation of mean Arctic precipitation from NCEP/NCAR and ERA reanalyses. J. Climate, 13, 182-201.

- and A. J. Etringer, 2002: Representation of Arctic precipitation in ERA-40. ECMWF ERA-40 Project Report Series 3, $16 \mathrm{pp}$.

- and R. G. Barry, 2005: The Arctic Climate System. Cambridge University Press, 385 pp.

— change in the northern high-latitude environment. Climatic Change, 46, 159-207.

- M. P. Clark, and D. H. Bromwich, 2003: Monitoring precipitation over the Arctic terrestrial drainage system: Data requirements, shortcomings, and applications of atmospheric reanalysis. J. Hydrometeor., 4, 387-407.

— A. P. Barrett, and F. Lo, 2005: Northern high-latitude precipitation as depicted by atmospheric reanalyses and satellite retrievals. Mon. Wea. Rev., 133, 3407-3430.

Sevruk, B., and W. R. Hamon, 1984: International comparison of national precipitation gauges with a reference pit gauge. WMO Instrument Observation Methods Rep. 17, 111 pp.

Stieglitz, M., J. Hobbie, A. Giblin, and G. W. Kling, 1999: Hydrologic modeling of an Arctic watershed: Towards pan-Arctic predictions. J. Geophys. Res., 104, 27 507-27 518.

_- A. Giblin, J. Hobbie, G. W. Kling, and M. Williams, 2000: Simulating the effects of climate change and climate variability on the carbon dynamics in Arctic tundra. Global Biogeochem. Cycles, 14, 1123-1136.

—, A. Ducharne, R. D. Koster, and M. J. Suarez, 2001: The impact of detailed snow physics on the simulation of snowcover and subsurface thermodynamics at continental scales. J. Hydrometeor., 2, 228-242.

, S. J. Déry, V. E. Romanovsky, and T. E. Osterkamp, 2003: The role of snow cover in the warming of Arctic permafrost. Geophys. Res. Lett., 30, 1721, doi:10.1029/2003GL017337.
Sturm, M., C. Racine, and K. Tape, 2001: Climate changeIncreasing shrub abundance in the Arctic. Nature, 411, 546547.

Uppala, S. M., and Coauthors, 2005: The ERA-40 re-analysis. Quart. J. Roy. Meteor. Soc., 131, 2961-3012.

U.S. Army Corps of Engineers, 1956: Snow Hydrology; Summary Report of the Snow Investigations. North Pacific Division, Corps of Engineers, 437 pp.

Vörösmarty, C. J., and Coauthors, 2001: The Hydrologic Cycle and its Role in Arctic and Global Environmental Change: A Rationale and Strategy for Synthesis Study. Arctic Research Consortium of the U.S., 84 pp.

Walsh, J. E., V. Kattsov, D. Portis, and V. Meleshko, 1998: Arctic precipitation and evaporation: Model results and observational estimates. J. Climate, 11, 72-87.

Wang, X., and J. R. Key, 2003: Recent trends in Arctic surface, cloud, and radiation properties from space. Science, 299, $1725-1728$.

Willmott, C. J., and K. Matsuura, 2001: Terrestrial air temperature and precipitation: Monthly and annual time series (19501999) (version 1.02). Center for Climate Research, University of Delaware.

Xie, P., and P. A. Arkin, 1997: Global precipitation: A 17-year monthly analysis based on gauge observations, satellite estimates, and numerical model outputs. Bull. Amer. Meteor. Soc., 78, 2539-2558.

Yang, D., B. E. Goodison, J. R. Metcalfe, V. S. Golubev, R. Bates, T. Pangburn, and C. L. Hanson, 1998: Accuracy of NWS 8 -inch standard non-recording precipitation gauge: Results of WMO intercomparison. J. Atmos. Oceanic Technol., 15, 54 68 .

- and Coauthors, 2000: An evaluation of the Wyoming gauge system for snowfall measurement. Water Resour. Res., 36, 2665-2677.

_- D. Kane, Z. Zhang, D. Legates, and B. Goodison, 2005: Bias corrections of long-term (1973-2004) daily precipitation data over the northern regions. Geophys. Res. Lett., 32, L19501, doi:10.1029/2005GL024057. 